\title{
A BIM-BASED APPROACH TO FAÇADE CLADDING OPTIMIZATION: GEOMETRICAL, ECONOMIC AND PRODUCTION CONTROL IN A DFMA PERSPECTIVE
}

\author{
Giuseppe Martino Di Giuda ${ }^{1}$, Paolo Ettore Giana ${ }^{1}$, Gabriele Masera ${ }^{1}$, Elena Seghezzi ${ }^{1}$, and Valentina Villa ${ }^{2}$ \\ ${ }^{1}$ Politecnico di Milano, Milano, Italy \\ ${ }^{2}$ Politecnico di Torino, Torino, Italy
}

\begin{abstract}
The goal of this paper is providing a methodology properly supporting façade optimization in a DfMA (Design for Manufacturing and Assembly) perspective. DfMA has proven to facilitate offsite manufacturing, lowering costs and improving speed and quality of construction, especially combined with BIM strategies. A BIM-based methodology can help in setting parameters for the proper optimization of the façade, balancing production related needs and design requirements. The proposed method allows the exploration of alternatives (known as Design Optioneering) to optimize the choice of façade elements. This method is based on a mathematical algorithm and script including parameters related to geometry, production waste management and designer's needs. The proposed methodology has been tested on a newly built school in Northern Italy.
\end{abstract}

\section{Introduction}

The building envelope plays a pivotal role in building design and construction, especially when considering sustainability goals. The envelope accounts for the most part of energy consumption, and represent a major cost item in the total value of a building (Huang \& Niu, 2016).

The building façade can be described as the separation layer between outside and inside, between nature and interior spaces occupied by people (Herzog, Krippner, \& Lang, 2012).

Depending on the outside conditions (in terms of climatic conditions, noise, mechanical loads, local resources and context), building facades modify and influence internal conditions (including temperature, light, air, sound level, visual relationship between outside and inside). For this reason, building facades are an increasingly relevant research area (Martinez, Patterson, Carlson, \& Noble, 2015).Building façade design faces a multiplicity of goals and needs. The envelope defines the architectural value of the building and in many cases, indicates the function of the building itself. Building façades are an environmental filter and play a relevant role in energy performance; they can host building services or devices to exploit renewable energy sources (e.g. photovoltaics or hot water panels), taking an active part in the building energy balance.

In this context, early stages of design have proven to play a pivotal role for success or failure of design (Granadeiro, Duarte, Correia, \& Leal, 2013); decisions taken in those stages have relevant impact on cost, time and effort of a project. Nonetheless, it is difficult to provide a complete outlook on choices and solutions in this phase, due to the limited amount of information available. In addition, a complete evaluation of design alternatives implies significant investments in terms of cost and time.

Several optimization strategies have been developed in recent years, mainly addressing energy and daylight aspects; a lack of consideration of production and installation issues can be underlined in this sense.

\section{Optimization in building design}

\section{The concept of optimization}

Complexity in architecture is a wide theme, that can regard many different aspects, from geometry and shape, to special structures and building systems (Bachman, 2008; Penttilä, 2006; Salingaros, 2016); a wide and deep analysis of this concept should involve all these fields and is beyond the scopes of the present work. Nonetheless, in this case, it is possible to define complexity as related to the high quantity of actors, goals, requirements to be fulfilled, involved in the process.

Architecture has been considered for a long time mainly an art-related activity. In the $70 \mathrm{~s}$, the introduction of optimization and numerical techniques allowed to keep into account structural and building services related issues in the architectural design of a building (Gero, 1975). Nowadays, the majority of existing approaches in terms of optimization are related to sustainability in building design (Evins, 2013). Optimization can be defined as the action of making the best or most effective use of a situation or a resource (Coello Coello, Lamont, \& van Veldhuizen, 2007). Considering building design, even in case of a 
limited number of constraints, this process is related to multiple goals and therefore multiple objective functions expressing these goals and requirements. For this reason, a multi-objective optimization is necessary to properly address this issue (Kalyanmoy, 2001) (Attia, Hamdy, O’Brien, \& Carlucci, 2013). Currently, different levels and approaches of optimization are available, depending on the tools used for the development. A first distinction in this sense is that between computational or algebraic and manual methods (Evins, 2013). The use of parametric based design tools is particularly useful as it allows to simulate many design alternatives, to visualize them, and to modify parameters in real time. The parameters expressing the variety of requirements involved in building design and construction can be divided in two main groups. The first group is that of design-related aspects, including energy performance, architectural quality, and comfort of the users. The second group is mainly related to construction requirements, and includes cost, production and waste management.

\section{Energy related optimization}

One of the first fields where building design optimization took place is related to energy and environmental impact. This trend is obviously associated to the implementation of sustainability standards, such as LEED or BREEAM. These standards are particularly useful in this sense as they provide a series of indicators or parameters to be maximized or minimized, in a hierarchic structure with a scoring system based on appropriately weighted credits (Lee \& Burnett, 2008; Suzer, 2015).

LEED and BREEAM, together with other major green buildings standards are mainly focusing on the use of renewable energies, energy efficiency, and indoor environmental quality. As a consequence, several optimization approaches are mainly focusing on energy efficiency, thermal performances and lighting quality. Most of these approaches address façade design, underlining the role of building envelope in the management of energy flows in buildings (Goia, Haase, \& Perino, 2013).

The multidisciplinary problem of building performance optimization is particularly challenging as it requires a huge amount of data from several disciplines. Some of existing approaches are trying to face this issue focusing on the combination and tradeoff between energy performance and internal comfort, considering both the building envelope and the building services, such as lighting, ventilation, heating and cooling (Andersen et al., 2008; Ascione, Bianco, De Stasio, Mauro, \& Vanoli, 2015; Bouchlaghem, 2000; Chantrelle, Lahmidi, Keilholz, Mankibi, \& Michel, 2011; Shaikh, Nor, Nallagownden, Elamvazuthi, \& Ibrahim, 2014).

\section{Form and structure optimization}

The shape of a building represents a primary feature, that defines its identity in terms of architecture, and has a relevant impact on energy performance, integration of building services, accessibility, urban setting. Contemporary architecture is moving towards complex geometries and forms, especially in the case of non-residential buildings.

Form optimization is therefore a consistent research field: usual approaches include cost-evaluation, glazing properties, heat losses (Granadeiro et al., 2013). In this sense, many approaches are keeping into account geometry together with structural properties, in order to optimize use of materials, and to provide light structures (Beghini, Beghini, Katz, Baker, \& Paulino, 2014; Rozvany, 2009; Sigmund, 2000), or considering solar radiation gain and efficiency (Fallahtafti, R., Mahdavinejad, 2015; Yi, H., Srinivasan, R.S., Braham, 2015; Yi, Y.K., Malkawi, 2012; Zhang, L., Zhang, L., Wang, 2016).

Some approaches are related to urban scale (Kämpf, J.H., Montavon, M., Bunyesc, J., Bolliger, R., Robinson, 2010; Morello, E., Gori, V., Balocco, C., Ratti, 2009), while others are addressing the building scale and its parts (Gustafsson, 2000; Nassar, Thabet, \& Beliveau, 2003).

\section{Limitations in current practices}

Besides providing valuable and useful support to practice and research, the proposed methodologies have relevant limitations in terms of constructionrelated requirements.

RIBA's stages expressing Life Cycle of a building, for instance, include:

- Strategic definition

- Preparation and brief

- Concept Design

- Developed Design

- Technical Design

- Construction

- Handover and Close out

- In Use

Most of the proposed methods do not take into account production related optimization or waste management; these approaches are mainly addressing the operational phases of the building life cycle (Banaitiene, Banaitis, Kaklauskas, \& Zavadskas, 2008).

Evaluating these aspects could be particularly challenging, as construction related requirements are strongly case-related; a one-fits-all approach is not possible.

Nonetheless, it is possible to provide a flexible methodology that could be adapted to single cases with minor changes. 


\section{Methodology}

Façade design is a complex task, as it involves a variety of constraints and requirements, expressing needs and goals of several actors involved in the process. Multi-objective optimization is particularly suitable to this kind of issues, as it allows to evaluate and maximize (or minimize) various parameters simultaneously (Marler \& Arora, 2004). The proposed approach is a Design Optioneering perspective, based on a multi-criteria and multi-objective optimization. This methodology allows optimizing design related aspects, and to include construction and production related constraints, towards a DfMA approach. The focus of optimization in this work is kept on design and construction related aspect rather than on production strategies.

\section{Multi-Criteria methodologies}

Multi-criteria is an effective methodology for non-linear problems (Alanne, 2004). Building façade design is a complex operation, that implies different criteria with mutual trade-offs, as previously stated. Using a multi-criteria methodology from the early stages of design could help in enhancing the effectiveness and reducing late variations, that results in cost and time increase. Current design procedures and existing tools in this context show limitations, connected to the wide variety of parameters to be taken into account: for this reason, it may be impossible to obtain complete optimality / maximization of all aspects, but compromise solutions can be found.

As previously stated, lacking aspects in current practice are related to manufacturability and production issues of the solution: there have been experiences of optimization in this field, but the aim of this research is the integration of manufacturability in a multi-dimensional matrix.

Besides the multi criteria decision making (MCDM) model choice, a multi-criteria methodology unfolds through several steps, as shown in Figure 1:

- Problem definition and goal formulation

- Identification of the criteria

- Weights estimation

- Score determination

- Classification of solutions

- Feedback

The goal of this methodology is choosing the most suitable strategy for buildings façades. The setting of goals helps in identifying the macro-areas, the criteria, and the indicators that can express in a quantitative way the criteria and the requirements.

The output of a multi criteria methodology is a classification of alternatives, that allows establishing the best solution (the one with the highest score).

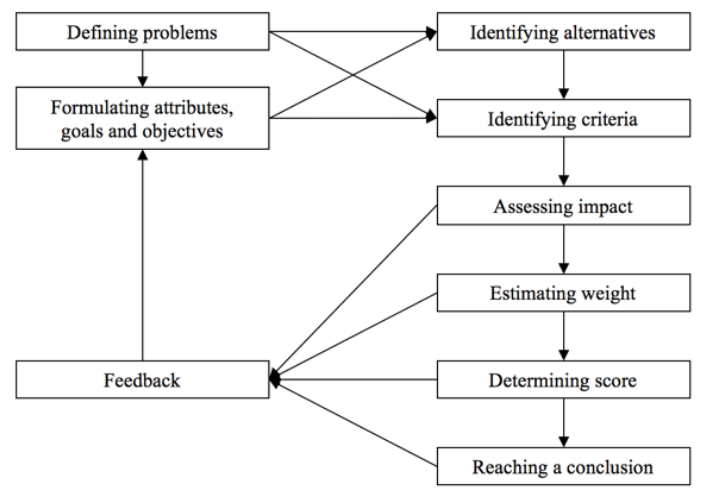

Figure 1: Multi-Criteria methodology scheme

\section{A DfMA perspective}

Design for Manufacturing and Assembly is a discipline stemming from the combination of DfA (Design for Assembly) and DfM (Design for Manufacturing), with the goal of simplifying the product structure to reduce the assembly cost and reducing the total parts cost. DfM provides estimation models of production cost and sensitivity analysis related to the variation of design and process parameters (Fox, Marsh, \& Cockerham, 2001); DfA is based on structural models for the estimation of the efficiency of assembly processes and possible improvements (Goulding, Pour Rahimian, Arif, \& Sharp, 2015). DfMA was first applied to mechanical industry, but it is nowadays spreading to other disciplines as an optimization strategy from early stages of design. DfMA's effectiveness is particularly evident as the approach provides a systematic procedure, that is quantitative and measurable. DfMA has proven to increase communication ease between the actors involved in building processes, offering simpler solutions with higher quality (Favi, Germani, \& Mandolini, 2016). During construction phases, a DfMA approach allows safer labor conditions and reduction in time and costs.

\section{A Design Optioneering approach}

A Design Optioneering approach is therefore proposed, based on the setting of requirements conveying the needs of actors of the process (Gerber, Lin, Pan, \& Solmaz, 2012). These requirements are expressed in a quantitative form as performance indicators. Each of them is then assigned a weight, in order to evaluate their mutual relevance, in a multicriteria perspective.

A certain degree of flexibility is provided, as the proposed approach is methodological and can therefore be modelled on the case: the chosen parameters can be changed, and a variation in the weights assigned to the parameters is useful to express the relevance of the actors. 
The evaluation of alternatives and the choice of the most suitable solution is therefore case-specific and modelled on the needs and goals of the actors.

\section{Development and case study application}

Complexity is an essential topic in AEC industry and Building Information Modelling allows an allembracing view and control of the project. The considered parameters play a relevant role in terms of complexity of design choices, as they are not based on the best solution in absolute terms, but on the one that fits better that particular project. The strategies should therefore be defined each time, based on the European Directives 23, 24 and 25/2014 (European Union, 2014). These Directives aim to an increase the freedom in the choice of the authorities, but also ask them more empowering skills.

The owner will define the criteria to be used to evaluate design choices, based on precisely defined needs. The presented case study is a school building located in Melzo (Italy), shown in Figure 2.

This case study is one of the last example of integrated tender, developed through a Most Economical Advantageous Tender (MEAT) procedure in Italian context. The construction phase lasts less than six months, without variations or controversies, thanks to a collaborative approach between designers and constructors.

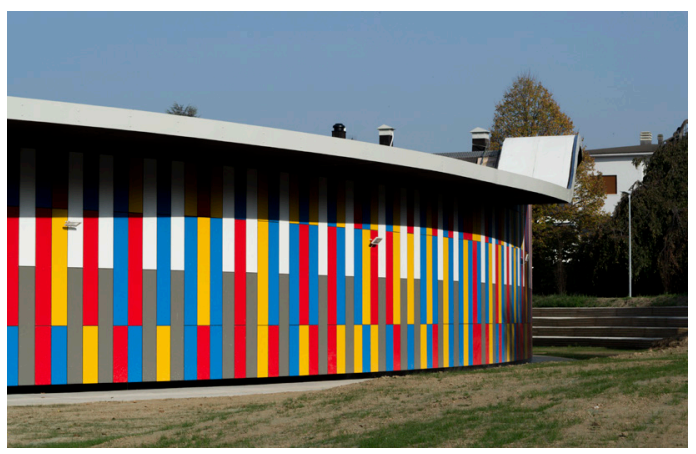

Figure 2: Melzo school: South façade

The school building, designed for 500 students, was developed as a research project in collaboration with the working group led by Prof. Giuseppe M. Di Giuda from Politecnico di Milano. The building is divided into three functionally and technologically different parts. The first one is a central reinforced concrete spin that connects all rooms with administrative function, such as teaching, library and auditorium. The second part is linked to the former through a central corridor, and it is composed by three blocks with a wooden structure. These contain teaching classrooms and workshops. The third part is a double height building made of precast concrete elements, hosting gymnasium, canteen and technical rooms.
The optimization process was applied to the design of the façade of the main building, interpreting goals and needs of constructors, designers, and producers. The curved ventilated façade is composed of a metal structure, linked by fixing brackets to the concrete wall. The metal structure, composed of t-shaped steel profiles, acts as support for the cladding, made of highpressure compact laminate panels.

The designers' choice was to create a color vibration using black, white, red, blue and yellow panels. Several issues regarding this façade were taken into account in the design and optimization phases: the curved geometry of the façade, the color variation required, the technological needs in terms of panels' sizes and shapes.

The all-embracing view of the project provided coherence thanks to a BIM approach.

The quantitative approach, reached through a multicriteria analysis, provides the process with a traceability of decisions.

\section{Use of extracted values to feed the algorithm}

The proposed methodology allows consistency of data to make further consideration, based on the result acquired from the model (Figure 3 ).

The required data to feed the algorithm have to be extracted directly from the model: for this reason, Dynamo plug-in, that is perfectly integrated in BIMbased software Revit, was chose to design and develop the algorithm. Dynamo allows to create design alternatives by means of variation in pre-set parameters. Through this methodology, the script acts directly on the model and, consequently, schedules and quantities are updated consistently with the designed model.

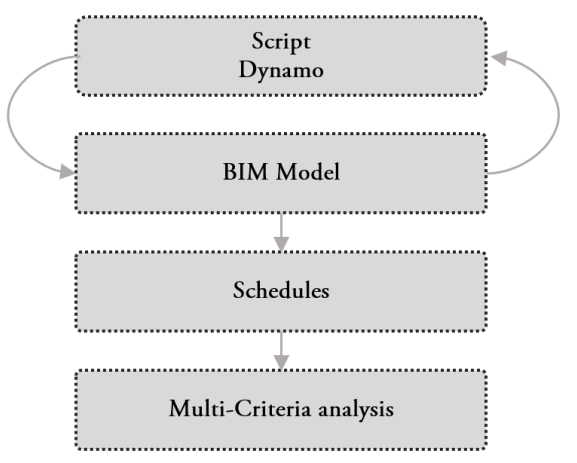

Figure 3: Data control

A common rule sets the basis to develop the script: a pattern composed by a black and white field and a sequence of random colored fields, in the range from one to five.

To create the pattern, the developed script requests four inputs: (i) the face of the geometry, (ii) the width 
of the panels, (iii) the height of the colored central panel and (iv) RGB colors for the random pattern. Dynamo takes geometrical information from a BIM model, such as shape, allowing users to create other geometries based on a mathematical algorithm, resulting therefore in an increase in quality and time management of design processes.

The essential advantage consists in the creation of a coherent and holistic interaction among different disciplines: information be automatically evaluated and the model can be consequentially updated, establishing a bidirectional flux of data.

The arithmetical approach to the algorithm consists in the creation of a function based on the geometry. Dynamo elaborates the geometrical input, and deduces a function, from which it calculates the total length of the façade. Later on, the script divides the functions by modules' width and places points. As the nodes between panels require a list of four points in clockwise order, a complete list to place all the needed components is prepared.

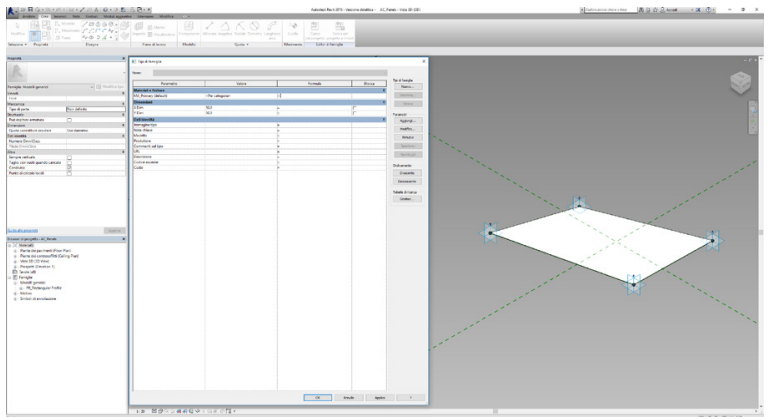

Figure 4: Adaptive components

An adaptive family is created and embedded with the required parameters (i.e. material, cost and dimensions, as shown in Figure 4), set as instances so the script can modify each of them individually.

The following step regards the placement of adaptive components on located points. In order to fulfill this requirement, the elaborated list of points is split in two separated lists. The first is obtained through the node that select items at index from the list of defined points. These indexes are obtained by a random selection among the predefined range and each item is summed to the previous one. (Figure 5) This process allows to place the sequence of colored panels. The second list is obtained through a subtraction of the list of colored panels from the list of all points. Through this script, both colored and black/white panels can be placed on the façade.

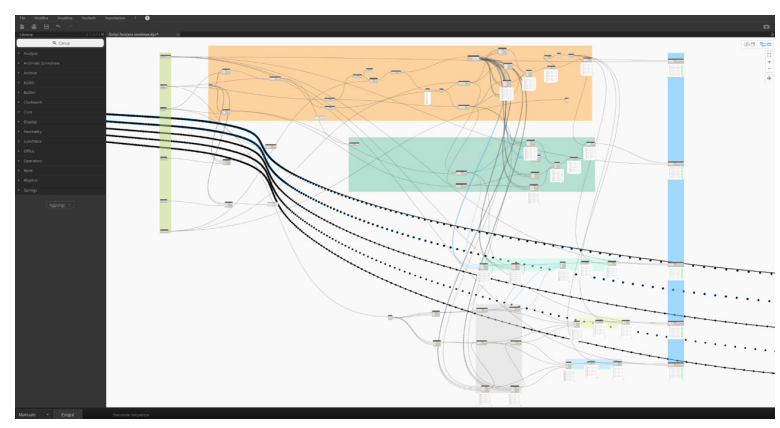

Figure 5: Dynamo script

\section{BIM Information to fulfill the algorithm}

This change of mind allows a different approach: namely it is possible to base a series of consideration, that are usually based on an economical point of view, with this method are instead performance based.

Through the quantity take off (Figure 6), it is possible to evaluate the real cost of the panels of a chosen solution through simple operations, based on manufacturing procedures (number of cuts).

Waste material resulting from cutting operations is also taken into account through a simple calculation.

Data are extracted for each design solution and inserted in an Excel sheet file. Data are elaborated through a macro to fulfill the algorithm and are compared with the other solutions. In this case, the algorithm is adapted to the contractors' needs: parameters and their weights are chosen on his discriminating factors, as later on shown. Namely, in this case, selected parameters were: (i) shape, (ii) costs, (iii) number of modules and (iv) waste material. As explained in the methodology, each parameter has its own weight, as shown in Table 1.

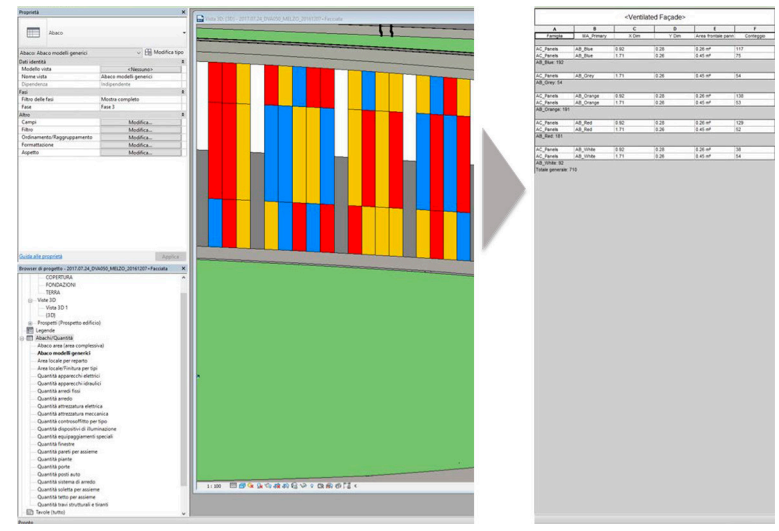

Figure 6: Production list

Shape factor is calculated comparing the geometry of the designed solution and the optimized one, divided by the initial geometry and re-parametrized between minimum and maximum values. The second factor is costs, evaluated on production operations and reparametrized between minimum and maximum values. The third parameter is the number of different 
modules' types used in the realization of the façade, considering the color variation.

The fourth factor is the waste material to produce the façade. It is calculated as the ratio of unused material to needed material to produce all panels and reparametrized between minimum and maximum value. Constructors' requests were considered in terms of impact on final cost. In particular, the number of modules to be used resulted as the most relevant factor in assembling period. Cutting processes to obtain the panels were set as the most relevant factor. Waste material and shape of the façade play a less relevant role, as shown in Table 1.

Table 1: Weight of parameters

\begin{tabular}{|c|c|c|c|c|c|}
\hline Parameters & i & ii & iii & iv & tot \\
\hline Weight & 20 & 30 & 30 & 20 & $\mathbf{1 0 0}$ \\
\hline
\end{tabular}

Four different solutions in terms of color variation and size were evaluated. The comparison can be carried out by applying the algorithm to different solutions, obtained through the script, with variations in panels width. As data are obtained directly from the model, all the panels, designed in the model, contain all the information needed for the evaluation. The script reparametrized from zero to one multiplied by the weight.

Table 2: Different solution comparison

\begin{tabular}{|c|c|c|c|c|c|c|}
\cline { 3 - 7 } \multicolumn{3}{c|}{} & \multicolumn{5}{c|}{ Parameters } & \multicolumn{1}{c|}{} \\
\cline { 2 - 7 } & & $\mathrm{i}$ & ii & iii & iv & tot \\
\cline { 2 - 7 } & 1 & 10 & 30 & 20 & 0 & $\mathbf{6 0}$ \\
\cline { 2 - 7 } & 2 & 20 & 30 & 30 & 15 & $\mathbf{9 5}$ \\
\cline { 2 - 7 } & 3 & 15 & 0 & 30 & 10 & $\mathbf{5 5}$ \\
\cline { 2 - 7 } & 4 & 0 & 20 & 20 & 20 & $\mathbf{6 0}$ \\
\hline
\end{tabular}

The selected solution was the number 2 , based on the final score obtained (as shown in Table 2).

\section{Discussion and conclusions}

\section{Advantages of the provided approach}

The presented approach could be applied to several stages of the design and construction process.

The possibility to adapt the chosen parameters on the needs of different actors and goals of the process results in fact in a certain degree of flexibility, that allows to apply this approach to different points of view of the process.

Considering decision related processes, it has to be noticed that currently a lack of transparency and legibility can be underlined. Some choices appear to be mainly based on previous experiences or expertise of the involved actors. This issue results in a decrease of productivity and effectiveness, as well as a lack of traceability of decisions throughout the process. It is nonetheless recognized that an efficient management of building design, together with knowledge management and communication, results in higher quality (Knotten, Lædre, \& Hansen, 2017). The proposed methodology could be helpful in this sense, as it provides a comparative evaluation on a quantitative base, enhancing control over decision processes. Furthermore, the decision process can be reevaluated in case of change of priority (i.e. change in parameters' weights). This process results in an increase in terms of efficiency of the whole workflow.

The result is consequently a tailored solution, based on stated needs; iterations in the methodology could be applied to provide a robust decision support tool.

\section{Current limitations and further application}

This methodology has been applied and developed through a specific case study, that has helped in validating it and providing the stage for further applications. A generalization of this method could regard its application to other case study buildings, with panelized façades or modular elements. Weights used for the parameters can be adjusted depending on needs of clients. Considering that a main focus of the proposed approach is related to dimensions, this approach could also be applied to partially opaque façade, including therefore transparent elements.

Some aspects related to the algorithm are currently not automated, that means that some calculations or evaluations need to be carried out manually from the designer or the contractor. Waste related aspects were calculated manually; a promising further aspect in this sense stems from the collaboration with manufacturers, in order to develop a partially automated evaluation of production related parameters. The collaboration with the supply chain in this sense could also be useful to potentially integrate further details related to manufacturing activities and production needs.

For these reasons, the proposed methodology will be tested on several case studies, to better understand and determine advantages provided and to refine the approach.

\section{Acknowledgements}

Authors acknowledge Eng. Francesco Paleari and Eng. Marco Schievano for their essential work on the case study development.

\section{References}

Alanne, K. (2004). Selection of renovation actions using multi-criteria "knapsack" model. Automation in Construction, 13(3), pp. 377-391.

Andersen, M., Kleindienst, S., Yi, L., Lee, J., Bodart, M., \& Cutler, B. (2008). An intuitive daylighting performance analysis and optimization approach. Building Research and Information, 36(6), pp. 593-607. 
Ascione, F., Bianco, N., De Stasio, C., Mauro, G. M., \& Vanoli, G. P. (2015). A new methodology for cost-optimal analysis by means of the multiobjective optimization of building energy performance. Energy and Buildings, 88, pp. 78-90.

Attia, S., Hamdy, M., O’Brien, W., \& Carlucci, S. (2013). Assessing gaps and needs for integrating building performance optimization tools in net zero energy buildings design. Energy and Buildings, 60, pp. 110-124.

Bachman, L. R. (2008). Architecture and the four encounters with complexity. Architectural Engineering and Design Management, 3.

Banaitiene, N., Banaitis, A., Kaklauskas, A., \& Zavadskas, E. K. (2008). Evaluating the life cycle of a building: A multivariant and multiple criteria approach. Omega, 36(3), pp. 429-441.

Beghini, L. L., Beghini, A., Katz, N., Baker, W. F., \& Paulino, G. H. (2014). Connecting architecture and engineering through structural topology optimization. Engineering Structures, 59, pp. 716726.

Bouchlaghem, N. (2000). Optimising the design of building envelopes for thermal performance. Automation in Construction, 10(1), pp. 101-112.

Chantrelle, F. P., Lahmidi, H., Keilholz, W., Mankibi, M. El, \& Michel, P. (2011). Development of a multicriteria tool for optimizing the renovation of buildings. Applied Energy, 88(4), pp. 1386-1394.

Coello Coello, C., Lamont, G. B., \& van Veldhuizen, D. (2007). A. Evolutionary Algorithms for Solving Multi-Objective Problems, Springer US.

European Union. Directive 2014/24/UE, Parlamento Europeo e del Consiglio del 26 febbraio 2014 sugli "appalti pubblici e che abroga la direttiva 2004/18/CE", L 94/65 Gazzetta ufficiale dell'Unione europea.

Evins, R. (2013). A review of computational optimisation methods applied to sustainable building design. Renewable and Sustainable Energy Reviews, 22, pp. 230-245.

Fallahtafti, R., Mahdavinejad, M. (2015). Optimisation of building shape and orientation for better energy efficient architecture. International Journal of Energy Sector Management, 9(4), pp. 593-618.
Favi, C., Germani, M., \& Mandolini, M. (2016). A Multi-objective Design Approach to Include Material, Manufacturing and Assembly Costs in the Early Design Phase. Procedia CIRP, 52, pp. 251-256.

Fox, S., Marsh, L., \& Cockerham, G. (2001). Design for manufacture: A strategy for successful application to buildings. Construction Management and Economics, 19(5), pp. 493-502.

Gerber, D. J., Lin, S.H.P., Pan, B.P., \& Solmaz, A. S. (2012). Design Optioneering: Multi-disciplinary Design Optimization through Parameterization, Domain Integration and Automation of a Genetic Algorithm. Symposium on Simulation for Architecture and Urban Design. Orlando, Florida, USA, pp. 23-30.

Gero, J. S. (1975). Architectural Optimization-a Review. Engineering Optimization, 1, pp. 189199.

Goia, F., Haase, M., \& Perino, M. (2013). Optimizing the configuration of a façade module for office buildings by means of integrated thermal and lighting simulations in a total energy perspective. Applied Energy, 108, pp. 515-527.

Goulding, J. S., Pour Rahimian, F., Arif, M., \& Sharp, M. D. (2015). New offsite production and business models in construction: priorities for the future research agenda. Architectural Engineering and Design Management, 11(3), pp. 163-184.

Granadeiro, V., Duarte, J. P., Correia, J. R., \& Leal, V. M. S. (2013). Building envelope shape design in early stages of the design process: Integrating architectural design systems and energy simulation. Automation in Construction, 32, pp. 196-209.

Gustafsson, S.-I. (2000). Optimization of insulation measures on existing buildings. Energy \& Buildings, 33(1), pp. 49-55.

Herzog, T., Krippner, R., \& Lang, W. (2012). Façade Construction Manual. Basel: Birkhäuser Edition Detail.

Huang, Y., \& Niu, J. (2016). Optimal building envelope design based on simulated performance: History, current status and new potentials. Energy and Buildings, 117, pp. 387-398.

Kalyanmoy, D. (2001). Multi-Objective Optimization using Evolutionary Algorithms. Wiley. 
Kämpf, J.H., Montavon, M., Bunyesc, J., Bolliger, R., Robinson, D. (2010). Optimisation of buildings' solar irradiation availability. Solar Energy, 84(4), pp. 596-603.

Knotten, V., Lædre, O., \& Hansen, G. K. (2017). Building design management - key success factors. Architectural Engineering and Design Management, 13(6), pp. 479-493.

Lee, W. L., \& Burnett, J. (2008). Benchmarking energy use assessment of HK-BEAM, BREEAM and LEED. Building and Environment, 43(11), pp. 1882-1891.

Marler, R. T., \& Arora, J. S. (2004). Survey of multiobjective optimization methods for engineering. Structural and Multidisciplinary Optimization, 26(6), pp. 369-395.

Martinez, A., Patterson, M., Carlson, A., \& Noble, D. (2015). Fundamentals in Façade Retrofit Practice. Procedia Engineering, 118, pp. 934-941.

Morello, E., Gori, V., Balocco, C., Ratti, C. (2009). Sustainable urban block design through passive architecture: A tool that uses urban geometry optimization to compute energy savings. In PLEA 2009 - Architecture Energy and the Occupant's Perspective: Proceedings of the 26th International Conference on Passive and Low Energy Architecture, Quebec, Canada.

Nassar, K., Thabet, W., \& Beliveau, Y. (2003). A procedure for multi-criteria selection of building assemblies. Automation in Construction, $12(5$ SPEC.), pp. 543-560.

Penttilä, H. (2006). Describing the changes in architectural information technology to understand design complexity and free-form architectural expression. Electronic Journal of Information Technology in Construction, 11, pp. 395-408.

Rozvany, G. I. N. (2009). A critical review of established methods of structural topology optimization. Structural and Multidisciplinary Optimization, 37(3), pp. 217-237.

Salingaros, N. (2014). Complexity in Architecture and Design. Oz Journal, 36(1), pp. 18-25.

Shaikh, P. H., Nor, N. B. M., Nallagownden, P., Elamvazuthi, I., \& Ibrahim, T. (2014). A review on optimized control systems for building energy and comfort management of smart sustainable buildings. Renewable and Sustainable Energy Reviews, 34, pp. 409-429.
Sigmund, O. (2000). Topology Optimization: A Tool for the Tailoring of Structures and Materials, Philosophical Transactions of the Royal Society of London. Series A: Mathematical, Physical and Engineering Sciences, 358(1765), pp. 211-227.

Suzer, O. (2015). A comparative review of environmental concern prioritization: LEED vs other major certification systems. Journal of Environmental Management, 154, pp. 266-283.

Yi, H., Srinivasan, R.S., Braham, W. W. (2015). An integrated energy-emergy approach to building form optimization: Use of EnergyPlus, emergy analysis and Taguchi-regression method. Building and Environment, 84, pp. 89-104.

Yi, Y.K., Malkawi, A. M. (2012). Site-specific optimal energy form generation based on hierarchical geometry relation. Automation in Construction, 26, pp. 77-91.

Zhang, L., Zhang, L., Wang, Y. (2016). Shape optimization of free-form buildings based on solar radiation gain and space efficiency using a multiobjective genetic algorithm in the severe cold zones of China. Solar Energy, 132, pp. 28-50. 